\title{
Perception and Information Seeking Behaviour of Rural Households towards Health Promoting Practices in Maigana District of Kaduna State, Nigeria
}

\author{
C. C. Ezeh1', O. H. Ezeh² \\ ${ }^{1}$ College of Agriculture, Ahmadu Bello University, Zaria, Nigeria \\ ${ }^{2}$ Department of Community Medicine, Ahmadu Bello University, Zaria, Nigeria \\ Email: Chukezeh14@gmail.com
}

How to cite this paper: Ezeh, C.C. and Ezeh, O.H. (2017) Perception and Information Seeking Behaviour of Rural Households towards Health Promoting Practices in Maigana District of Kaduna State, Nigeria. Open Journal of Medical Psychology, 6, 233-242.

https://doi.org/10.4236/ojmp.2017.64019

Received: September 1, 2017

Accepted: October 28, 2017

Published: October 31, 2017

Copyright $\odot 2017$ by authors and Scientific Research Publishing Inc. This work is licensed under the Creative Commons Attribution International License (CC BY 4.0).

http://creativecommons.org/licenses/by/4.0/

\section{(c) (i) Open Access}

\begin{abstract}
Information is valuable, increases understanding and reduces uncertainty. Limited knowledge and access to health promoting and disease prevention programmes are more pronounced in rural than urban areas of Nigeria. Furthermore, the paucity of healthcare services in these rural communities also contributes to the prevalence of health challenges in the rural sector. This study investigated the perception and information seeking behavior of rural households in Maigana District of Kaduna State, Nigeria towards health promoting practices. A random sample of 152 respondents selected from five of eleven wards in the district was interviewed using a pre-tested structured questionnaire. The results, based on a 4-point Likert type scale and benchmark of 2.5 showed a very poor perception of health promoting practices among the respondents. Also, the information needs of the respondents were shown to be enormous. Three of the six socio-demographic variables regressed were found to significantly influence the information seeking behavior of the respondents regarding health promoting practices. Constraints limiting the embracement of health promoting practices were identified and measures aimed at promoting healthier living standards in rural communities were recommended. The study concludes that vast knowledge gaps do exist coupled with the poor perception of HPPs by the respondents.
\end{abstract}

\section{Keywords}

Perception, Information, Health Promoting, Rural Households 


\section{Introduction}

In both the developed and developing world, many rural residents must travel substantial distances for primary medical care, requiring significantly longer travel time to reach care than their urban counterparts [1]. Evidence indicates that rural residents have limited access to health care and that rural areas are often underserved by primary health practitioners [2], in their study of some rural communities in Northern Nigeria.

Buttressing this point [3] affirmed that the majority of the villagers had no ready access to modern health facilities and where such services existed; the facilities were understaffed and poorly equipped.

Beside the inadequacy or non-existence of health care facilities and services in rural areas, the residents lack information on basic healthcare and health promoting requirements. Information is valuable, increases understanding and reduces uncertainty. Invariably, limited information about a subject results in limited knowledge of same. In Nigeria, limited knowledge and access to health promoting and disease prevention programmes are more pronounced in the rural than urban areas [3]. No doubt, low knowledge and practice of health promoting practices in rural communities account for the prevalence of health challenges there. According to [4], factors that serve as barriers to knowledge and practice of health promoting practices include ignorance, resistance to change, low literacy levels, cultural traits and low incomes. Also, there are environmental exposures that are hazardous to healthy living.

Generally, the benefits of imbibing health promoting practices in rural communities are numerous and include:

1) Reduced healthcare costs [5];

2) Increased productivity of farm and off-farm activities [6];

3) Improved sense of well being [7];

4) Enhanced self esteem [7];

5) Reduction in morbidity and mortality [3]

Given constrained medical care systems in rural communities, health promotion is key to reducing the significant burden of chronic diseases [5]. What is the level of awareness and perception of rural folks regarding health promoting practice? What are their information needs and how do they seek information on health promoting practices? These questions underscore the importance of this study aimed at evaluating the perception and information seeking behavior of rural households in Maigana District of Kaduna State, Nigeria. Specifically, the study sought to:

1) Describe the socio-demographic characteristics of the respondents.

2) Evaluate their perception and information seeking behavior regarding health promoting practices.

3) Determine the variables that influence the embracement of health promoting practices.

4) Identify the constraints/barriers to health promoting practices in the study area. 


\section{Conceptual Framework}

The American Bureau of Census [8] classifies a group of people living in a community with a population of not more than 2500 as rural, whereas the [9] defines a community with less than 20,000 people as rural. According to [10] rural areas are easily identified by various criteria besides population, such criteria include the level of infrastructural development, i.e. road network, educational institutions, water supply, electricity, healthcare facilities, and communication. Typically, rural dwellers are less vocal, characterized by a culture of poverty, as most people barely live above subsistence level [11]. As posited by [12], about 90 percent of the rural workforces engage directly or indirectly in agriculture.

Generally speaking, information is that which informs, i.e. can answer to a question. Information relates to knowledge communicated, received or learned concerning a particular fact, subject or circumstance. Information seeking behavior includes "those activities a person may engage in when identifying their own needs for information, seeking for such information in any way and using or transferring such information" [13]. According to [14], information behavior is the totality of human behavior in relation to sources and channels of information including both active and passive information seeking and information use. He went further to describe information seeking behavior as purposive seeking of information as a consequence of a need to satisfy some goal. Corroborating this view, [15] affirmed that information seeking behavior refers to the way people search for and utilize information. In all, the ultimate goal in information search is to use information gathered to satisfy information needs.

\section{Methodology of the Study}

Maigana is an area within Soba Local Government Area located in the north eastern part of Kaduna State. The area is predominantly rural and farming is the main occupation.

Purposive and random sampling techniques were used to select the district and five out of eleven wards namely; Danwata, Gamagira, Soba, Rahama and Turawa. A random sample of 32 households per ward was selected and the women were interviewed using a pre-tested structured questionnaire. The women in the households were interviewed since they were directly involved with most of the HPPs evaluated in this study, e.g. breastfeeding, immunization, food preparation and handling. Two female field assistants, who were fluent in Hausa language, were engaged for six weeks to cover the 160 respondents in the five wards. At the end of the exercise, 152 questionnaires were assessed as duly completed and constituted the sample size for the study (95\% retrieval rate). Data collated were analyzed using descriptive statistics to achieve objective 1, 4 and partly 2 while a 4-point Likert type scale was used to evaluate perception. Lastly, Linear Regression analysis was used to determine the socio-demographic variables influencing the information seeking behavior of the household regarding health promoting 
practices by the respondents. Specifying the regression model, the independent variables age, marital status, educational level, family size, tribe and religion were represented as $\mathrm{x}_{1}, \mathrm{x}_{2}, \mathrm{x}_{3}, \mathrm{x}_{4}, \mathrm{x}_{5}$ and $\mathrm{x}_{6}$ respectively, $\mu$ being the error term.

\section{Results and Discussion}

The findings of the study are discussed under the following subheadings:

\section{Socio-Demographic Characteristics of Respondents}

Results in Table 1 showed that $52.6 \%$ of the respondents were aged between 20 - 39 years while $20.4 \%$ were aged between 50 - 59 years; the mean age for the

Table 1. Distribution of respondents based on socio-demographic characteristics.

\begin{tabular}{|c|c|c|}
\hline Characteristics & Frequency $(\mathrm{F})$ & Percentage (\%) \\
\hline \multicolumn{3}{|l|}{ Age } \\
\hline 20 - 29 years & 28 & 18.4 \\
\hline $30-39$ years & 52 & 34.2 \\
\hline $40-49$ years & 45 & 29.6 \\
\hline 50 - 59 years & 27 & 17.8 \\
\hline Mean & 39.2 & \\
\hline \multicolumn{3}{|l|}{ Marital status } \\
\hline Single & 3 & 1.9 \\
\hline Married & 128 & 84.2 \\
\hline Divorced & 7 & 4.6 \\
\hline Widowed & 14 & 9.3 \\
\hline \multicolumn{3}{|l|}{ Educational status } \\
\hline Primary education & 39 & 25.6 \\
\hline Secondary education & 22 & 14.5 \\
\hline Tertiary education & 7 & 4.6 \\
\hline No formal education & 84 & 55.3 \\
\hline \multicolumn{3}{|l|}{ Household size (numbers) } \\
\hline $1-10$ & 112 & 73.7 \\
\hline $11-20$ & 28 & 18.4 \\
\hline $21-30$ & 12 & 7.9 \\
\hline \multicolumn{3}{|l|}{ Tribe } \\
\hline Hausa & 118 & 77.6 \\
\hline Others & 34 & 22.4 \\
\hline \multicolumn{3}{|l|}{ Religion } \\
\hline Christianity & 27 & 17.8 \\
\hline Islam & 125 & 82.2 \\
\hline
\end{tabular}

Source: Field Study (2016). 
sample was 39.2 years. The majority of the respondents $(84.2 \%)$ were married; only $1.9 \%$ were single, while $14 \%$ were either divorced or widowed. The majority of households (73.7\%) had 1 - 10 members, $18.4 \%$ had 11 - 20 members, while only $7.9 \%$ had 21 and above members.

The educational status of the respondents was generally low; not surprising considering the rural nature of the study area. About $27 \%$ of the respondents had primary education, $16.4 \%$ secondary education, while only $5.9 \%$ had tertiary education. Majority of them (55.3\%) had no formal education. Other socio-demographic characteristics recorded showed that Hausa's constituted $77 \%$ of the study sample while with respect to religion, majority of the respondents $(82.2 \%)$ were Moslems.

\section{Perception and Information Seeking Behaviour}

The perception of the rural households regarding health promoting practices was evaluated using a 4-point Likert-type scale and 16 items relating to basic Health Promoting Practices (HPPs). The scales are Strongly Agree (SA-4), Agree $(A=3)$, Disagree $(\mathrm{D}=2)$ and Strongly Disagree $(\mathrm{SD}=1)$.

Using a benchmark of 2.5, the results in Table 2 showed that only 6 items (2, $3,5,11,13$ and 16) had mean scores above 2.5 , indicating positive perception. The remaining 10 items (62.5\%) had mean scores ranging from $2.09 \%$ (item 7 ) to 2.49 (item 10 . Implicitly, only $37.5 \%$ of the 16 items evaluated were perceived

Table 2. Perception of respondents regarding basic health promoting practices.

\begin{tabular}{|c|c|c|c|c|c|c|c|}
\hline $\mathrm{S} / \mathrm{N}$ & Health Promoting Practices & $\begin{array}{c}\text { SA } \\
\text { F (\%) }\end{array}$ & $\begin{array}{c}\text { A } \\
\text { F (\%) }\end{array}$ & $\begin{array}{c}\mathrm{D} \\
\mathrm{F}(\%)\end{array}$ & $\begin{array}{c}\text { SD } \\
\text { F (\%) }\end{array}$ & $\begin{array}{l}\text { Agg. } \\
\sum \mathrm{x}\end{array}$ & $\begin{array}{c}\text { Mean } \\
\bar{x}\end{array}$ \\
\hline 1 & Avoiding stagnant water/gutters around the house & $32(21.1)^{*}$ & $39(25.7)^{\star}$ & $45(29.6)$ & $36(23.7)^{*}$ & 371 & 2.44 \\
\hline 2 & Covering cooked /leftover foods & $71(46.7)$ & $45(29.6)$ & 2416.8) & $12(7.9)$ & 479 & $3.15^{* *}$ \\
\hline 3 & Timely immunization of infants & $43(28.3)$ & $56(36.8)$ & $30(19.7)$ & $23(15.1)$ & 423 & $2.78^{* *}$ \\
\hline 4 & Eradication of insects and rodents & $24(15.8)$ & $44(28.9)$ & $56(36.8)$ & $28(18.4)$ & 368 & 2.42 \\
\hline 5 & Cleanliness of surroundings & $82(53.9)$ & $48(31.6)$ & $22(14.5)$ & $0(0)$ & 516 & $3.39^{* *}$ \\
\hline 6 & Exclusive breastfeeding (6 months) & $33(21.7)$ & $41(30)$ & $43(28.3)$ & $35(23)$ & 376 & 2.47 \\
\hline 7 & Frequent fumigation of surroundings & $18(11.8)$ & $32(21.1)$ & $51(33.6)$ & $48(31.6)$ & 318 & 2.09 \\
\hline 8 & Balancing family diets & $31(20.4)$ & $36(23.7)$ & $57(34.2)$ & $28(18.4)$ & 374 & 2.46 \\
\hline 9 & Always boil family drinking water & $27(17)$ & $32(21.1)$ & $52(34.2)$ & $38(25)$ & 346 & 2.27 \\
\hline 10 & Antenatal checkups in pregnancy & $32(21.1)$ & $42(27.6)$ & $47(30)$ & $31(20.4)$ & 375 & 2.49 \\
\hline 11 & Observe oral/dental hygiene & $72(47.7)$ & $64(41.1)$ & $16(10.5)$ & $0(0)$ & 572 & $3.37^{* *}$ \\
\hline 12 & Child spacing/family planning & $34(22.4)$ & $39(25.7)$ & $41(30)$ & $38(25)$ & 373 & 2.45 \\
\hline 13 & Sleeping in ventilated rooms & $38(25)$ & $43(28.3)$ & $49(32.2)$ & $23(15.1)$ & 402 & $2.64^{* *}$ \\
\hline 14 & Regular exercise/aerobic workouts & $27(17.8)$ & $33(21.7)$ & $48(31.6)$ & $44(30)$ & 347 & 2.28 \\
\hline 15 & Regular consumption of fruits and vegetables & $25(16.4)$ & $44(30)$ & $58(38.2)$ & $25(16.4)$ & 372 & 2.45 \\
\hline 16 & Sleeping under insecticide treated mosquito nets & $41(27)$ & $37(24.3)$ & $40(26.3)$ & $34(22.4)$ & 389 & $2.56^{* *}$ \\
\hline
\end{tabular}

Source: Field Study (2016). Notes: ${ }^{*}$ Figure in parenthesis represents percentages; ${ }^{* *}$ mean $\bar{x}>2.5$. 
as critical health promoting practices by the respondents. It is important to note the adverse implications of some of the items not perceived as critical to healthy living by the respondents e.g. poor antenatal checkups, leaving stagnant water around the house and non-observance of exclusive breastfeeding. These and other items poorly perceived contribute significantly to the prevalence of health challenges in rural communities as corroborated by [4] and [7].

The study also sought to elicit the sources of information used by the respondents on health promoting practices.

In general, the sources itemized in Table 3 recorded low patronage by the respondents. Besides, the top three ranking sources (Community Health Workers, Radio and Self-Help/Women Groups), the other sources were poorly utilized, the least ranking (internet) having zero patronage. Again, the very dismal use of the internet for information on health promoting practices is attributable to the rural nature of the area and the low literacy status of most respondents. The ranking of rural extension health workers (CHOs) as the main source of information indicates the huge potentials in utilizing this source for sustainable and robust rural health policies and programmes. These findings are similar to those of [16] in their study of healthcare seeking behavior of rural dwellers in Southern Nigeria.

Further on information search and utilization, the study sought to appraise the respondents' information needs on specific health promoting practices. The responses are shown in Table 4.

The results in Table 4 indicated a generally low propensity for information search on basic health promoting practices by the respondents. Based on a benchmark of 1.5 , none of the 16 items evaluated made the mark. Information on treated nets, antenatal checkups, timely immunization and exclusive breastfeeding was fairly sought with mean values of $1.39,1.36,1.24$ and 1.15 respectively. Exclusive breastfeeding was followed by child spacing/family planning

Table 3. Distribution of respondents based on information sources on HPPS.

\begin{tabular}{cccc}
\hline Information Source & Frequency & Percentage & Ranking \\
\hline Newspapers & 4 & 2.6 & 8 \\
Television & 13 & 8.6 & 2 \\
Radio & 34 & 22.4 & 6 \\
Children & 12 & 7.9 & 1 \\
Community Health Officers (CHOs) & 52 & 34.2 & 3 \\
Friends/Neighbours & 29 & 19.1 & 7 \\
Parents & 8 & 5.3 & 4 \\
Self-Help/Women Groups & 22 & 14.5 & 9 \\
Internet & 0 & 0 & - \\
\hline
\end{tabular}

Source: Field Study (2016). Note: ${ }^{\star}$ Multiple responses recorded. 
Table 4. Information needs for specific health promoting practices.

\begin{tabular}{|c|c|c|c|c|c|}
\hline $\mathrm{S} / \mathrm{N}$ & Specific Information/Practice & $\begin{array}{c}\text { Not } \\
\text { sought }(0)\end{array}$ & $\begin{array}{c}\text { Partially } \\
\text { sought (1) }\end{array}$ & $\begin{array}{c}\text { Greatly } \\
\text { sought (2) }\end{array}$ & $\begin{array}{c}\text { Mean } \\
(\bar{x})\end{array}$ \\
\hline 1 & Avoid stagnant water/gutters & $82(53.9)^{*}$ & $44(28.9)^{*}$ & $26(17.1)^{*}$ & 0.63 \\
\hline 2 & Covering cooked food/leftover foods & $69(45.4)$ & $41(30)$ & $42(27.6)$ & 0.82 \\
\hline 3 & Timely immunization of infants & $36(23.7)$ & $44(28.9)$ & $72(47.4)$ & 1.24 \\
\hline 4 & Eradication of insects and rodents & $71(46.7)$ & $56(36.8)$ & $25(16.4)$ & 0.53 \\
\hline 5 & Cleanliness of surroundings & $53(34.9)$ & $53(34.9)$ & $47(30.9)$ & 0.96 \\
\hline 6 & Exclusive breastfeeding (6 months) & $45(29.6)$ & $61(40.1)$ & $57(37.5)$ & 1.15 \\
\hline 7 & Frequent fumigation of surroundings & $72(42.4)$ & $59(38.8)$ & $21(13.8)$ & 0.66 \\
\hline 8 & Balancing family diets & $53(34.9)$ & $48(31.6)$ & $51(33.6)$ & 0.97 \\
\hline 9 & Always boil family drinking water & $81(53.3)$ & $57(37.5)$ & $14(9.2)$ & 0.56 \\
\hline 10 & Antenatal checkups in pregnancy & $23(15.1)$ & $51(33.6)$ & $78(51.3)$ & 1.36 \\
\hline 11 & Observe oral/dental hygiene & $69(95.4)$ & $52(34.2)$ & $31(20.4)$ & 0.75 \\
\hline 12 & Child spacing/family planning & $47(30.9)$ & $50(32.9)$ & $55(36.2)$ & 1.05 \\
\hline 13 & Sleeping in ventilated rooms & $82(53.9)$ & $54(35.5)$ & $16(10.5)$ & 0.57 \\
\hline 14 & Regular exercise/aerobic workouts & $77(50.7)$ & $41(30)$ & $34(22.4)$ & 0.72 \\
\hline 15 & Regular consumption of fruits and vegetables & $87(57.2)$ & $48(31.6)$ & $47(30.9)$ & 0.903 \\
\hline 16 & Sleeping under treated nets & $19(12.5)$ & $54(35.5)$ & $79(52)$ & 1.39 \\
\hline
\end{tabular}

Source: Field Study (2016). Note: ${ }^{*}$ Figures in parenthesis represent percentages.

with a mean value of 1.05 . The rest of the items had mean values less than 1 ranging from 0.53 (eradication of insects and rodents) to 0.97 (balanced family diets). Evidently, the information gap is enormous, implying that the information needs of the respondents regarding health promoting practices are equally huge.

Relationship between Socio-Demographic Characteristics and Information Seeking Behaviour

The regression analysis result in Table 5 showed that age $(r=0.027)$, educational status $(\mathrm{r}=0.534)$ and family size $(\mathrm{r}=0.285)$ were statistically significant at $P<0.05$; they significantly influenced the information seeking behavior of the respondents on health promoting practices. The remaining three variables-marital status, tribe and religion—did not significantly influence information seeking behavior.

\section{Constraints Limiting the Embracement of Health Promoting Practices}

In the course of the study, the respondents were asked to indicate factors that limited their perception, information seeking behavior and even their propensity to embrace basic health promoting practices. Their responses are shown in Table 6 .

The results in Table 5 showed that poor incomes, limited knowledge of HPPs and unavailability of primary health care facilities were identified as major constraints 
Table 5. Regression coefficient of relationship between socio-demographic characteristics and information seeking behaviour.

\begin{tabular}{cccc}
\hline Socio-Demograhic Variable & Coefficient & Std. Error & Significance \\
\hline Age & 0.027 & 0.104 & $0.264^{*}$ \\
Marital status & -0.122 & 0.021 & 0.022 \\
Educational attainment & 0.534 & 0.138 & $0.003^{*}$ \\
Family size & 0.285 & 0.127 & $0.029^{*}$ \\
Tribe & -0.008 & 0.012 & 0.673 \\
Religion & -0.026 & 0.041 & 0.542 \\
\hline
\end{tabular}

Source: Field Study (2016). Note: ${ }^{*}$ Significant at $P<0.05$ level.

Table 6. Distribution of respondents based on constraints limiting embracement of HPPs.

\begin{tabular}{ccc}
\hline Constraints & Frequency & Percentage \\
\hline Limited knowledge of HPPs & 75 & 49.3 \\
Unavailability of primary healthcare facilities & 66 & 43.4 \\
Poor incomes & 81 & 53.3 \\
Low literacy level & 52 & 34.2 \\
Shortage of rural health workers (CHOs) & 61 & 40.1 \\
Long distances to primary health centres (PHCs) & 56 & 36.8 \\
Total & $391^{*}$ & \\
\hline
\end{tabular}

Source: Field Study (2016). Note: ${ }^{*}$ Multiple responses recorded.

to embracing HPPs; ranking first, second and third in order of severity. These were followed by shortage of CHOs, long distances to PHCs and low literacy levels. While identifying poor incomes as a major constraint, it is important to note that most of the HPPs highlighted in this study require more of knowledge and attitude than money. Limited information and knowledge are related to unavailability of PHCs, shortage of CHOs, low literacy level and even long distances to PHCs.

\section{Conclusions and Recommendations}

This study has shown that vast knowledge gaps do exist among rural dwellers regarding HPPs. Also shown and related, is the generally low perception of basic HPPs by the respondents. Limited information and knowledge, low literacy levels and the sheer isolation of living in remote areas all conspire to mitigate the struggles of rural dwellers to lead normal healthy life. No doubt, these constraints and their consequences manifest in the prevalence of health challenges in these rural communities than we have in urban areas. The need for policies and programmes that will reduce the burden of morbidity and mortality in the rural areas is germane and cannot be over-emphasized. The following recommendations are aimed at addressing the issues thrown up by the findings of this study 
and promoting healthy rural living standards:

1) Concerted efforts to increase rural health services and utilization by having health care facilities that are within reach, well staffed and reasonably equipped.

2) There is need to upscale federal, state and local government initiatives towards the training and recruitment of rural health workers to man the PHCs and address the huge information gaps that exist presently.

3) Having in place a robust and sustainable programme aimed at sensitizing and increasing the knowledge base of rural dwellers on basic HPPs. This could be done on monthly or quarterly basis at the PHCs by trained PHWs.

4) Recognizing the peculiar challenges that rural areas present especially as they relate to infrastructure deficits, e.g. water supply, Primary Health Centres/Facilities and access roads.

\section{References}

[1] Van Nostrand, J.F. (1993) Common Beliefs about the Rural Elderly: What Do National Data Tell Us? Vital Health Statistics, 3, 1-79.

[2] Kletke, P.R., Marder, W.D. and Wike, R.J. (1991) A Projection of the Primary Care Physician Population in Metropolitan and Non-Metropolitan Areas Primary Care Research: Theory and Methods. AHCPR Confluence Proceedings, Washington DC, 261-269.

[3] Murphy, M. and Baba, T.M. (1996) Rural Dwellers and Health Care in Northern Nigeria. Social Science and Medicine, 15, 265-271.

[4] Egunjobi, I. (2012) Promotion of Rural Environmental Sanitation through Traditional Financial Intermediaries. Health Promotion International, 3, 341-346.

https://doi.org/10.1093/heapro/3.4.341

[5] Robinson, K.J., Driedger, M.S., Elliot, S.J. and Eyles, J.C. (2006) Understanding Facilitators of and Barriers to Health Promoting Practices. Health Promotion Practice, 7, 467-476. https://doi.org/10.1177/1524839905278955

[6] Stocks, R. (1983) Distance and the Utilization of Health Facilities in Rural Nigeria. Social Science \& Medicine, 17, 563-570. https://doi.org/10.1016/0277-9536(83)90298-8

[7] Strasser, R. (2003) Rural Health around the World; Challenges and Solution. Family Practice, 20, 457-463. https://doi.org/10.1093/fampra/cmg422

[8] American Bureau of Census (ABC) (2008) National Population Report. ABC, Washington DC.

[9] Federal Office of Statistics (FOS) (1995) Multiple Indicator Cluster Survey. (National) Federal Office of Statistics, Abuja.

[10] Afolayan, S.O. (2001) Community Mobilization in Rural Development in Bangladesh: Lessons for Nigeria. ARMTI, Ilorin.

[11] Laah, D.E., Abba, M., Ishaya, D.S. and Gana, J.N. (2013) The Mirage of Rural Development in Nigeria. Journal of Social Science and Public Policy, 5, 11-21.

[12] Nyagba, S. (2009) Review of Nigeria's Rural Policies for Sustainable Development. Business Round Table, Abuja.

http://democracy-africa.org/warc/OVERVIEW\%20OF\%20NIGERIA'S\%20POLICY \%20by\%20Dr\%20Nyagba.pdf

[13] Wilson, T.D. (2000) Uncertainty in Information Seeking. Final Report to the British 
Library Research and Innovation Centre, $163 \mathrm{p}$.

[14] Donald, O.C. (2002) Looking for Information: A Survey of Research on Information Seeking Needs and Behaviour. Academic-Press, New York, 370 p.

[15] Nicolaisen, J. (2006) Compromised Needs and the Label Effect: An Examination of Claims and Evidence. Journal of the Association for Information Science and Technology, 60, 114-121.

[16] Iyalombe, G.S. and Iyalombe, S.I. (2012) Health Seeking Behaviour of Rural Dwellers in Southern Nigeria: Implications for Healthcare Professions. International Journal of Tropical Disease \& Health, 2, 62-71.

https://doi.org/10.9734/IJTDH/2012/973 